\title{
O ATUAL E AS TENDÊNCIAS DO ENSINO E DA PESQUISA EM GEOGRAFIA NO BRASIL
}

\author{
Dirce Maria Antunes Suertegaray
}

Resumo: Este artigo faz uma análise do ensino e da pesquisa em Geografia no Brasil, com base na formação de profissionais em programas de PósGraduação. Foi definido que o produto final dos Mestrados e Doutorados, dissertações e teses, expressa essas duas dimensões conjuntamente: 0 ensino e a pesquisa. Considerando esta idéia, foi analisada a produção dos 29 Programas de Pós-Graduação recomendados pela CAPES. A produção levantada corresponde ao período 2000-2003. Com estes dados e considerando os títulos dos trabalhos, foram classificados estes em sub-campos e escalas de análise em Geografia. Os resultados indicam um deslocamento da análise na Geografia Física para Geografia Ambiental e uma predominância da Geografia Humana sobre os demais campos analisados, além do predomínio da análise em escala local.

Palavras-chave: Geografia; Pesquisa; Ensino.

\section{Introdução}

0 desafio de falar sobre este tema é grande. Trata-se de um tema abrangente que reúne duas temáticas fundamentais: ensino e pesquisa no campo da Geografia em escala nacional. Inúmeros são os caminhos para esta abordagem. Após uma longa reflexão optamos por seguir o caminho do ensino e da pesquisa na Pósgraduação. Isto, porque tratar de ensino em termos de graduação seria algo que despenderia muito tempo para uma análise que correspondesse à dimensão do território. Segundo, porque, mais recentemente, em virtude de minha proximidade com a PósGraduação, a coleta de informações foi mais facilitada. Terceiro, porque avalio que neste nivel de ensino é onde a pesquisa e 0 ensino não aparecem dissociados, o que é fundamental, em meu entendimento, na discussão da temática.

Penso ser importante discutir a conexão ensino e pesquisa, compartilho com a perspectiva relativa à educação, presente em MATURANA (1994). Na sua compreensão:

Educar é um processo entre sujeitos, crianças e adultos, que se dá pelo convívio e, ao conviver há transformações recíprocas e espontâneas. 0 educar ocorre, portanto, todo o tempo. Para este autor este processo favorece a constituição de uma história no conviver que faz com que as pessoas aprendam a viver, de uma maneira que se configura, segundo o conviver da comunidade aonde vivem.

Por sua vez, pesquisar implica em responder questões, responder perguntas. Perguntas que nos instigam. A pesquisa implica em buscar respostas às nossas dúvidas, curiosidades em relação ao mundo e a nós neste mundo.

Portanto, o vínculo da pesquisa com a educação é evidente. 0 processo de pesquisa/investigação é, também, um processo de auto-conhecimento, ou seja, o reconhecimento de nós no mundo. Para Rubem ALVES (2003), produzir conhecimento científico, semelhantemente, ao conhecimento relativo ao senso comum, resulta da necessidade de "compreender o mundo, a fim de viver melhor e sobreviver". 0 que distingue 0 senso comum do conhecimento científico seria o refinamento deste, além da busca da objetividade, sistematização, ordem e predição. Portanto, pesquisar é uma forma de aprender, de compreender, de explicar 0 mundo em que vivemos. Trata-se de uma habilidade que, principalmente neste momento histórico, torna-se "ferramenta" básica. Conforme já indicado em outro momento "significa dizer que se educamos sem a prática da investigação científica, não estamos oferecendo esta forma de convivência e de percepção do mundo, ou seja, aquela que advém da pesquisa, a nossos alunos e educandos". (SUERTEGARAY, 2002).

É com base nestes pressupostos que me dedico, brevemente, a analisar 0 ensino e a pesquisa na Pós-Graduação. $E ́$, no meu entendimento, neste nível de ensino que estes dois elementos (ensino e pesquisa) aparecem em conexão. Aqui o aluno aprende perguntando-se e construindo uma resposta, portanto, pesquisando. Isto, porque sabemos que na estrutura dos programas de Pós-Graduação o tempo dedicado a pesquisa é, teoricamente, total. 
Por outro lado, os temas investigados expressam atualidades e tendências e, na grande maioria, refletem, como já disse, interesses de respostas a questões que instigam os jovens alunos em formação acadêmica.

Penso, portanto, que o mapeamento da produção brasileira na Pós-Graduação em Geografia nos permittiu essa reflexão. Ela representa 0 ensino e a pesquisa, revela as tendências da Geografia e muito mais do que isto indica as necessidades e/ou questionamentos feitos pelos jovens em relação ao mundo que os rodeia.

Para fazer esta análise, avaliei, a partir da produção de teses e dissertações dos 29 programas distribuídos em território nacional, alguns elementos que podem indicar, através do título do trabalho, atualidade e tendências. Para tanto, levantei duas dimensões que norteiam minhas preocupações: a escala de análise e os subcampos da Geografia. Considerando a escala, classifiquei os trabalhos nas escalas local, regional, nacional e abrangência internacional. A definição dos campos temáticos (sub-unidades da Geografia) não foi feita a priori, resultou da análise do conjunto de dissertações e teses, portanto, constituiu elemento de indicação de tendência. Observei, para 0 conjunto dos dados, temas relativos à Geografia Física, Geografia Humana, Ambiente, Educação e Geografia, Teoria e Método em Geografia.

Para pensar a atualidade, foi feita uma análise temporal que considera um período de 4 (quatro) anos (2000/2003). 0 limite em 2003 ocorre devido à disponibilidade dos dados no sítio da CAPES, de onde extraímos estas informações.

Os cursos analisados são em número de 29. Deste conjunto, foram extraídos os cursos novos cujos dados de dissertações defendidas não estão, ainda, registrados. No conjunto eles são sete (7) cursos: UNICAMP, UERJ, UFC, UFPB-JP, UFMT, UFPA e UFSM.

Os dados que seguem apresentam, na forma de tabelas, 0 resultado desta avaliação. Duas questões básicas nortearam esta proposta: investigar em que escala de análise se concentra a produção geográfica que demanda dos cursos de Pós-Graduação e, como está representado na formação acadêmica 0 ensino/pesquisa da Geografia Física. Esta segunda questão, penso ser fundamental, na medida em que estamos, neste momento, num fórum de debate da Geografia Física. Diz respeito, também, a um questionamento que vimos fazendo, ao longo dos anos 90 , qual seja 0 de que a Geografia Física como campo específico e integrado não apresenta representatividade analítica no contexto geográfico. A fragmentação da Geografia Física promoveu 0 fortalecimento de campos específicos com autonomia interpretativa.
Cabe exemplificar com a Geomorfologia, esta constitui um saber científico que se configura pela busca de interpretação do relevo. Desde sua constituição, construíram-se diferentes teorias como Ciclo Geográfico, Pediplanação e Pedimentação, Equilíbrio Dinâmico, Sistemas Morfogenéticos, Probabilística, Etchplanação, entre outras. Estas teorias sustentadas por diferentes encaminhamentos metodológicos e concepção de tempo-espaço expressam, cada uma a sua maneira e em seu tempo, possibilidades de interpretação das formas de relevo sob diferentes escalas. No âmbito da Geografia Física não temos estas construções, temos, como expressou BERTRAND (1972) no título de seu trabalho, esboço metodológico, ou seja, propostas analíticas, caminhos metodológicos e não teorias explicativas da natureza em seu conjunto. Além disto, os dados mais atuais aqui levantados indicam que a compartimentação da Geografia Física em seus diferentes segmentos (climatologia, geomorfologia, biogeografia, hidrologia e outros) tem levado à diminuição de produção. Aqui me refiro em âmbito geográfico. A pergunta então é: para onde vai a Geografia Física?

Ao analisar alguns eventos no Brasil e na América Latina, buscando informações sobre esta questão, já se evidenciava (SUERTEGARAY e NUNES, 2001) uma tendência à ampliação da análise ambiental em detrimento da Geografia Física. Chamei a atenção para isto, mas para muitos colegas esta observação não fazia sentido.

Nesta nova investigação, percebo, pelos dados mostrados mais adiante, que há uma redução do conteúdo ensinado/pesquisado em Geografia Física na Pós-Graduação. Entretanto, observo uma ampliação da análise ambiental. Aqui cabe uma ressalva, quando me refiro à Geografia Física estou considerando-a como um sub campo da Geografia que objetiva interpretar a natureza, não estou me referindo à natureza, assim como não considero Geografia Física "sinônimo" de natureza. Podemos não andar bem com a Geografia Física, porém 0 conhecimento da natureza no contexto geográfico continua sendo imprescindível, portanto, dele não devemos abrir mão.

\section{Para onde vai a Geografia Física?}

Esta questão norteia a análise que fiz relativa à produção da Geografia nos cursos de Pós-Graduação. As tabelas que seguem permitem visualizar o movimento da Geografia. A primeira apresenta as dissertações e teses agrupadas por sub-campo de estudo geográfico, mais especificamente a Geografia Humana, Geografia Física, Ambiente, Ensino, Teoria e Método. A análise deste conjunto nos permite algumas considerações. 
Dos 23 cursos com registro de dados tem-se 11 cursos com produção geográfica predominante na Geografia Humana ou superando a Geografia Física nesses quatro (4) anos da análise. São eles: UFBA, UNB, UFGO, UFMG, UFU, UFPE, UFF, FUFSE, UNESP-PP, USP/GH, PUC/ MINAS. Observa-se que a UFRJ e a
UFSC têm forte produção em Geografia Humana, entretanto, no conjunto da produção a distribuição é mais eqüitativa entre as áreas. Três cursos podem ser visualizados como de forte tradição nas humanidades: USP/GH, UNESP/PP e UFRJ.

Tabela 1 Teses e dissertações em Geografia de 2000 a 2003, por tema. Fonte: CAPES (2005).

\begin{tabular}{|c|c|c|c|c|c|c|c|c|c|c|}
\hline \multirow[t]{2}{*}{ Programa } & \multicolumn{2}{|c|}{ Geogr. Física } & \multicolumn{2}{|c|}{ Geog. Humana } & \multicolumn{2}{|c|}{ Ambiente } & \multicolumn{2}{|c|}{ Teoria e Método } & \multicolumn{2}{|c|}{ Ensino } \\
\hline & (un) & $(\%)$ & (un) & $(\%)$ & (un) & $(\%)$ & (un) & $(\%)$ & (un) & $(\%)$ \\
\hline UFRJ & 42 & 19,5 & 60 & 8,1 & 18 & 5,8 & 7 & 9,2 & 2 & 3,0 \\
\hline USP-GF & 39 & 18,1 & 0 & 0,0 & 48 & 15,5 & 6 & 7,9 & 9 & 13,4 \\
\hline UFU & 32 & 14,9 & 46 & 6,2 & 11 & 3,5 & 1 & 1,3 & 14 & 20,9 \\
\hline UFSC & 24 & 11,2 & 47 & 6,4 & 25 & 8,1 & 0 & 0,0 & 1 & 1,5 \\
\hline UNESP-RC & 21 & 9,8 & 32 & 4,3 & 19 & 6,1 & 5 & 6,6 & 3 & 4,5 \\
\hline UFMG & 13 & 6,0 & 34 & 4,6 & 21 & 6,8 & 8 & 10,5 & 9 & 13,4 \\
\hline UEM & 12 & 5,6 & 14 & 1,9 & 19 & 6,1 & 2 & 2,6 & 5 & 7,5 \\
\hline PUC-MINAS & 8 & 3,7 & 23 & 3,1 & 6 & 1,9 & 0 & 0,0 & 1 & 1,5 \\
\hline UFPE & 6 & 2,8 & 27 & 3,6 & 4 & 1,3 & 1 & 1,3 & 1 & 1,5 \\
\hline UNESP-PP & 3 & 1,4 & 90 & 12,2 & 22 & 7,1 & 2 & 2,6 & 6 & 9,0 \\
\hline UFGO & 3 & 1,4 & 34 & 4,6 & 14 & 4,5 & 4 & 5,3 & 4 & 6,0 \\
\hline UFPR & 3 & 1,4 & 15 & 2,0 & 19 & 6,1 & 1 & 1,3 & 1 & 1,5 \\
\hline UFBA & 2 & 0,9 & 39 & 5,3 & 3 & 1,0 & 0 & 0,0 & 0 & 0,0 \\
\hline UNB & 2 & 0,9 & 24 & 3,2 & 11 & 3,5 & 0 & 0,0 & 0 & 0,0 \\
\hline UFRGS & 2 & 0,9 & 10 & 1,4 & 9 & 2,9 & 1 & 1,3 & 5 & 7,5 \\
\hline FUFMS & 2 & 0,9 & 3 & 0,4 & 1 & 0,3 & 0 & 0,0 & 0 & 0,0 \\
\hline UEL & 1 & 0,5 & 5 & 0,7 & 3 & 1,0 & 1 & 1,3 & 0 & 0,0 \\
\hline USP-GH & 0 & 0,0 & 173 & 23,4 & 38 & 12,3 & 31 & 40,8 & 6 & 9,0 \\
\hline UFF & 0 & 0,0 & 32 & 4,3 & 5 & 1,6 & 6 & 7,9 & 0 & 0,0 \\
\hline UFSE & 0 & 0,0 & 26 & 3,5 & 3 & 1,0 & 0 & 0,0 & 0 & 0,0 \\
\hline UFRN & 0 & 0,0 & 3 & 0,4 & 3 & 1,0 & 0 & 0,0 & 0 & 0,0 \\
\hline FUNECE & 0 & 0,0 & 3 & 0,4 & 8 & 2,6 & 0 & 0,0 & 0 & 0,0 \\
\hline UFPA & 0 & 0,0 & 0 & 0,0 & 0 & 0,0 & 0 & 0,0 & 0 & 0,0 \\
\hline UFC & 0 & 0,0 & 0 & 0,0 & 0 & 0,0 & 0 & 0,0 & 0 & 0,0 \\
\hline UFPB/JP & 0 & 0,0 & 0 & 0,0 & 0 & 0,0 & 0 & 0,0 & 0 & 0,0 \\
\hline UNICAMP & 0 & 0,0 & 0 & 0,0 & 0 & 0,0 & 0 & 0,0 & 0 & 0,0 \\
\hline UERJ & 0 & 0,0 & 0 & 0,0 & 0 & 0,0 & 0 & 0,0 & 0 & 0,0 \\
\hline UFSM & 0 & 0,0 & 0 & 0,0 & 0 & 0,0 & 0 & 0,0 & 0 & 0,0 \\
\hline UFMT & 0 & 0,0 & 0 & 0,0 & 0 & 0,0 & 0 & 0,0 & 0 & 0,0 \\
\hline TOTAL & 215 & 100,0 & 740 & 100,0 & 310 & 100,0 & 76 & 100,0 & 67 & 100,0 \\
\hline
\end{tabular}

Desloca-se, em nosso entendimento, o eixo da análise da Geografia Física para a Ambiental. Para o conjunto dos cursos analisados, todos apresentam produção neste tema. Merece destaque a Pós-Graduação em Geografia da USP/GF, onde os dados indicam um deslocamento da análise da Geografia Física para a Ambiental. Para 0 conjunto de teses e dissertações produzidas nestes quatro anos analisados tem-se: 39 classificadas como Geografia Física e 48 como relativas à análise ambiental. 
Observei estar esta temática também presente no programa USP/GH. Neste, registrei no período, 38 dissertações e teses no contexto da discussão ambiental.

Registrei, também, a produção geográfica de muitos programas, basicamente dividida entre Geografia Humana e Ambiental, aparecendo de forma muito reduzida a produção na Geografia Física. Cito, neste caso, UFRGS e UFPR. Considerando a produção em números absolutos, quatro cursos destacam-se na produção, no âmbito da análise ambiental USP/GF, USP/GH, UFSC e UNESP/RC.

Embora os dados indiquem uma diminuição da análise no campo da Geografia Física e um deslocamento para 0 ambiental, cursos no país que apresentam produção de destaque nesta área são, por exemplo, a UFRJ, USP/GF, UFSC e UFU.

Os temas abordados no conjunto da produção brasileira no contexto ambiental estão associados a estudos de impactos ambientais, diagnósticos, zoneamentos, monitoramentos, além dos estudos de risco ambiental. Em geral, esses estudos estão assentados sob o espaço urbano, bacias hidrográficas, parques $\mathrm{e}$ reservas nacionais.

Os estudos de Geografia Física foram agrupados, de acordo com 0 volume da produção, em três grupos. 0 primeiro grupo é relativo a temas como a morfodinâmica, movimentos de massa e processos erosivos, solos, redes e canais, meio físico, compartimentação e morfogênese do relevo e dinâmica do clima. Um segundo grupo diz respeito aos estudos relativos às formas costeiras, à fauna e flora e à dinâmica de sedimentos e perda de solo por erosão. 0 terceiro grupo está representado pelos estudos de relevo cárstico, de geoecologia e aproveitamento energético.

Os dados levantados permitem-me dizer que, na atualidade, existe uma forte tendência aos estudos ambientais e, conseqüentemente, um deslocamento dos estudos compreendidos como Geografia Física para esta área. Esta formulação com certeza poderá ser mal interpretada neste Simpósio de Geografia Física, no entanto, cabe registrar mais uma vez que não se trata de dizer que a Geografia abandonou os estudos da natureza, trata-se de observar 0 deslocamento e, conseqüentemente, a mudança de ótica analítica. Estas são para mim evidentes. Continuamos e devemos continuar incorporando a natureza na análise geográfica, continuamos tendo e devemos ter nos currículos, disciplinas que nos ensinem a análise da natureza. Agora, devemos refletir sobre os conceitos e as denominações ainda atribuídas a essas novas formas de compreender o mundo.

A Geografia Física, de meu ponto de vista, constituiu um rótulo para definir nossos estudos sobre natureza, porém não constitui um campo analítico que dê sustentação à compreensão da natureza em seu conjunto.

Muitos geógrafos viram no método sistêmico uma possibilidade de entender a natureza de forma integrada e atribuíram à natureza uma dimensão sistêmica. Enquanto meu argumento é de que a natureza não é sistêmica, mas sim que ela pode ser analisada sistemicamente. Em sendo assim, o sistemismo não é uma teoria interpretativa da natureza, constitui um caminho analítico - um método.

MONTEIRO (2000) em seu livro onde faz referência ao sistêmico, fala em história de uma procura. Deixa evidente que, ao longo de sua produção em Geografia, procurou um método, estudou e construiu suas análises sob um caminho (o método sistêmico). Diferentemente da análise sistêmica funcionalista que (tradicional) incorpora o tempo e seus ritmos na análise.

Constitui, na minha avaliação, 0 advento da questão ambiental associada ao sistemismo um dos elementos que desloca a análise. Na medida em que se observa que a falta de compreensão das conexões, devido a compartimentação científica, nos leva, hoje, à crise do conhecimento. Somos levados à reflexão e a pensar novas formas de conexão. Essa busca constitui hoje uma discussão no âmbito científico e filosófico. Esta, por sua vez expressa a exigência demandada da complexidade do mundo moderno e da emergência da problemática ambiental.

Este deslocamento analítico que os dados revelam, associado às mudanças de método, a busca da compreensão da funcionalidade mais do que da gênese na atualidade, nos permite vislumbrar 0 estado atual e as tendências da Geografia, derivadas da Geografia Física para as análises de conexão entre natureza e sociedade. Ainda que os dados revelem uma predominância do ensino/pesquisa no campo das humanidades (a chamada Geografia Humana), não há como deixar de exigir na formação do profissional de Geografia o conhecimento da natureza.

Os dados absolutos sobre 0 conjunto da produção dos cursos de Pós-Graduação nos permitem apontar sobre esta tendência. Neste período produziram-se, em Geografia Humana, 740 trabalhos (entre teses e dissertações). Na Geografia Física a produção foi de 215 teses e dissertações, um número menor em relação às teses e dissertações produzidas sobre temas ambientais (310).

Outros elementos foram considerados nesta análise: a produção relativa ao ensino e a construção/reflexão sobre Teoria e Método em Geografia (aqui se incluí um conjunto de trabalhos no âmbito da cartografia).

Na perspectiva do ensino, a produção em números ainda é 
pequena, 67 produtos em 4 anos. Esta produção está representada em 14 dos 23 cursos com registro de produção. Destes, oito (8) não registram teses e dissertações sobre ensino em Geografia. A produção mais regular sobre ensino aparece representada nos cursos das universidades: UFU, USP/GF, UFMG, UNESP/PP, USP/GH, UEM e UFRGS.

No que se refere a teses e dissertações relativas a Teoria e
Método em Geografia a produção é de 76 , para 0 período em análise, entre teses e dissertações. Os trabalhos teóricos encontram-se concentrados em seis cursos (USP/GH, UFMG, UFRJ, UFF, USP/GF e UNESP/RC). Destas, destacadamente, a maior contribuição à discussão teórica e metodológica advém da USP/GH.

Tabela 2 Teses e dissertações em Geografia de 2000 a 2003, por escala espacial. Fonte: CAPES (2005).

\begin{tabular}{|c|c|c|c|c|c|c|c|c|}
\hline \multirow[t]{2}{*}{ Programa } & \multicolumn{2}{|c|}{ Local } & \multicolumn{2}{|c|}{ Regional } & \multicolumn{2}{|c|}{ Nacional } & \multicolumn{2}{|c|}{ Internacional } \\
\hline & (un) & $(\%)$ & (un) & $(\%)$ & (un) & $(\%)$ & (un) & $(\%)$ \\
\hline USP-GH & 132 & 13,3 & 51 & 24,4 & 18 & 40,0 & 1 & 50,0 \\
\hline UNESP-PP & 95 & 9,5 & 19 & 9,1 & 3 & 6,7 & 0 & 0,0 \\
\hline UFSC & 79 & 7,9 & 3 & 1,4 & 0 & 0,0 & 0 & 0,0 \\
\hline UFMG & 67 & 6,7 & 5 & 2,4 & 0 & 0,0 & 0 & 0,0 \\
\hline USP-GF & 66 & 6,6 & 19 & 9,1 & 1 & 2,2 & 0 & 0,0 \\
\hline UFRJ & 61 & 6,1 & 29 & 13,9 & 7 & 15,6 & 1 & 50,0 \\
\hline UFU & 58 & 5,8 & 12 & 5,7 & 0 & 0,0 & 0 & 0,0 \\
\hline UNESP-RC & 54 & 5,4 & 14 & 6,7 & 3 & 6,7 & 0 & 0,0 \\
\hline UFGO & 50 & 5,0 & 5 & 2,4 & 0 & 0,0 & 0 & 0,0 \\
\hline UEM & 47 & 4,7 & 8 & 3,8 & 0 & 0,0 & 0 & 0,0 \\
\hline UFRGS & 41 & 4,1 & 8 & 3,8 & 1 & 2,2 & 0 & 0,0 \\
\hline UFBA & 40 & 4,0 & 4 & 1,9 & 0 & 0,0 & 0 & 0,0 \\
\hline UFPR & 38 & 3,8 & 0 & 0,0 & 0 & 0,0 & 0 & 0,0 \\
\hline UFF & 31 & 3,1 & 5 & 2,4 & 1 & 2,2 & 0 & 0,0 \\
\hline UFPE & 31 & 3,1 & 6 & 2,9 & 0 & 0,0 & 0 & 0,0 \\
\hline UFSE & 29 & 2,9 & 0 & 0,0 & 0 & 0,0 & 0 & 0,0 \\
\hline PUC-MINAS & 23 & 2,3 & 6 & 2,9 & 8 & 17,8 & 0 & 0,0 \\
\hline UNB & 23 & 2,3 & 9 & 4,3 & 3 & 6,7 & 0 & 0,0 \\
\hline FUNECE & 10 & 1,0 & 2 & 1,0 & 0 & 0,0 & 0 & 0,0 \\
\hline FUFMS & 9 & 0,9 & 1 & 0,5 & 0 & 0,0 & 0 & 0,0 \\
\hline UEL & 7 & 0,7 & 1 & 0,5 & 0 & 0,0 & 0 & 0,0 \\
\hline UFRN & 4 & 0,4 & 2 & 1,0 & 0 & 0,0 & 0 & 0,0 \\
\hline UFPA & 0 & 0,0 & 0 & 0,0 & 0 & 0,0 & 0 & 0,0 \\
\hline UFC & 0 & 0,0 & 0 & 0,0 & 0 & 0,0 & 0 & 0,0 \\
\hline UFPB/JP & 0 & 0,0 & 0 & 0,0 & 0 & 0,0 & 0 & 0,0 \\
\hline UNICAMP & 0 & 0,0 & 0 & 0,0 & 0 & 0,0 & 0 & 0,0 \\
\hline UERJ & 0 & 0,0 & 0 & 0,0 & 0 & 0,0 & 0 & 0,0 \\
\hline UFSM & 0 & 0,0 & 0 & 0,0 & 0 & 0,0 & 0 & 0,0 \\
\hline UFMT & 0 & 0,0 & 0 & 0,0 & 0 & 0,0 & 0 & 0,0 \\
\hline TOTAL & 995 & 100,0 & 209 & 100,0 & 45 & 100,0 & 2 & 100,0 \\
\hline
\end{tabular}




\section{Em que escala espacial trabalhamos?}

No âmbito da produção geográfica outra questão que está presente em minhas preocupações corresponde à escala de análise. Para avaliar esta questão classifiquei o mesmo conjunto de teses e dissertações considerando as escalas local, regional, nacional e global. Observou-se que não há trabalhos em escala global. 0 que existe são trabalhos elaborados em espaços/ temas extra território nacional. Considerando importante dimensionar esta questão, denominei esta de abrangência Internacional, embora a análise possa ser, por vezes, em escala local e/ou regional (Tabela 2).

A Tab. 2 representa esta abordagem. Observei, com base na tabela que origina essas representações, que é predominante a abordagem em escala local. Das dissertações e teses defendidas para 0 conjunto dos 22 programas com informações, tem-se um registro de 995 indicando análises em escala local. Este número é relevante se considerarmos que, em escala regional foram classificados 209 produtos e, em escala nacional 46. As informações atribuídas à abrangência internacional são apenas duas, no período, e restritas aos cursos da UFRJ e USP/GH.

A análise local constitui uma tendência na Geografia atual. Não necessariamente a indicação de um espaço local pode circunscrever a análise ao local. 0 que aqui parece ser importante registrar é o direcionamento do tema à explicação local. Esta é uma tendência que se configura pela demanda de conhecimento e, por vezes, gestão de espaços como bairros, áreas centrais, assentamentos rurais, bacias hidrográficas, parques e reservas ou territorialidades urbanas dos mais diferentes matizes.

Esta tendência obscurece a dimensão regional e nacional e indica também, uma mudança de rumo. Por algum tempo, entendeu-se a Geografia como campo do conhecimento que deveria decifrar a região ou 0 território, mais recentemente, além destes conceitos serem reconfigurados, temos 0 advento do lugar como pertencimento, identidade e possibilidade de ampliação de cidadania, além da compreensão de que 0 cotidiano é parte fundante das nossas ações e de possibilidade de transformação. Já indica Milton SANTOS (1996) que estamos no mundo a partir do lugar e que devíamos compreender o mundo a partir do lugar, espaço de coexistência e de ações compartidas.

Seguramente, esta abordagem desvenda realidades antes não reveladas e exige reformulação de conceitos. Entretanto, visualizei uma diminuição da análise e compreensão do espaço geográfico em outras escalas também significativas. Em particular, faço referência à escala regional, por exemplo, na análise geomorfológica. Esta dimensão pouco abordada não nos permite avançar na compreensão, por exemplo, dos grandes conjuntos de relevo ou domínios naturais. Assim, permanecemos com informações, quiçá, desatualizadas.

$\mathrm{Na}$ escala nacional, da mesma forma, carecemos de entendimento do Brasil na sua abrangência. Constitui para nós um grande desafio quando nos é solicitado pensar uma temática como, por exemplo, o desmatamento em escala nacional, entre outros temas. A Geografia do Brasil como resultante da temática geográfica produzida em escala nacional está para ser reconstruída. Perdemos essa dimensão.

Sei que os ouvintes desta fala poderão estar pensando da impossibilidade de tratar esta escala em teses e dissertações. Certamente a complexidade é maior, porém não é impossível. As produções no âmbito regional são em maior número construídas nas universidades USP/GH, UFRJ, UNESP/PP, USP/GF, UNESP/RC. É possivel que nestes casos a tradição dos estudos regionais ainda esteja presente, e que sendo estas as pioneiras no ensino da Pós-Graduação tragam em seus quadros a preocupação com a demanda regional.

No âmbito dos estudos em escala nacional, observei uma menor abrangência. A produção mais expressiva, dos estudos em escala nacional, está vinculada à USP/GH, UFRJ em maior proporção, seguidas da UNB e PUC/MINAS, neste caso enfatizando a análise de dados estatísticos via novas tecnologias.

Esta análise da atualidade e das tendências em Geografia, no que pese a sua abordagem restrita, permite algumas reflexões, em particular neste fórum de debates sobre Geografia Física.

\section{Conclusão}

Procurei retratar duas tendências, a do deslocamento dos tradicionais estudos no campo da Geografia Física para o campo do Ambiente, configurando-se como nova tendência frente às demandas da sociedade contemporânea. $E, 0$ da análise desta temática predominantemente em escala local, configurando-se um expressivo conhecimento pontual em detrimento do conhecimento regional ou nacional. Sem negar a importância desta tendência penso que cabe uma reflexão, ou cabe perguntar:

Frente à lacuna observada em termos de análise da natureza brasileira em escalas nacionais e regionais sob pressupostos mais atualizados, pergunta-se: 0 que nos cabe fazer? Esta lacuna é o legado que penso ser 0 que minha geração está deixando em aberto ao futuro. Caberia, no período das redes e das conexões, um esforço de superação desta perspectiva, ou esta já não é efetivamente necessária?

Para finalizar, cabe registrar que, embora a tendência de 
deslocamento da Geografia Física para a análise ambiental seja evidente, não se trata, como já afirmei anteriormente, de negar a necessidade, cada vez mais premente, do conhecimento da natureza, mesmo que esta em si não possa ser mais purificada, configurando-se neste momento histórico como híbrida.

Enfim penso e quero deixar registrado que somos portadores de um legado histórico enquanto ciência de conexão. Ao percorrermos outros campos de conhecimento verificaremos que a articulação entre natureza e sociedade, já concebida, como possibilidade na origem da Geografia, hoje é colocada como fundamental. Com visões diferenciadas de articulação podemos evidenciar esta discussão em SERRES (1990), LATOUR (1994), SANTOS (1996), HARVEY (1993 e 2004), LEFF (2001), entre outros. Este repensar indica a necessidade de nós, geógrafos, penetrarmos nesse debate trazendo nossa contribuição e, ao mesmo tempo, apreendendo que, para além de nossas heranças, há uma discussão que se instala sobre natureza e que, por razões óbvias, devemos estar presentes.

Este debate indica conexão entre natureza e sociedade ou construção de um contrato natural (SERRES, 1990); constituição de um mundo híbrido onde objetos criados na atualidade não têm possibilidades de serem reconhecidos sob estatutos ou constituições em separado - natureza e sociedade (LATOUR, 1994). Indica ainda a possibilidade de pensarmos uma natureza artificial ou cibernética (SANTOS, 1996; HARVEY, 2004) e ainda mais, indica a necessidade de percebermos que o conceito de natureza não é natural conforme já foi dito por GONÇALVES (1989). Portanto, enquanto expressão da cultura pode ser pensado como naturezas - culturas a maneira de LATOUR (1994) ou de LEFF (2001).

Indo mais adiante caberia deixar registrado que nesta discussão se interpenetram várias dimensões e conhecimentos sendo necessário registrar a importância da construção atual de um saber sobre a configuração de um mundo que permita 0 diálogo, 0 conhecimento técnico e os saberes denominados tradicionais.

Embora as ações em Geografia Física (hoje deslocada para a análise ambiental) sempre demandaram significativo conhecimento técnico, novas formas de produção do espaço geográfico exigem de nós a participação, no que LEFF (2001) denominou saber ambiental. 0 debate necessário é, segundo este autor, mais relativo à concepção de natureza e de ambiente que ainda adotamos do que propriamente as ações objetivas sobre 0 mundo exterior. Novos saberes, portanto, são necessários para entendermos 0 mundo e nele podermos agir. 
SUERTEGARAY, D.M.A. (2005). Nowadays and trends in Geography teaching and research in Brazil. Revista do Departamento de Geografia, n. 16, p. 38-45.

Abstract: This paper makes an analysis of teaching and research in Brazil, based in the professionals' formation in Geography graduation programs. It was defined that the final product of the Master's degrees and Doctorates, dissertations and thesis, expressed those two dimensions together: teaching and research. Considering this idea, the production of the 29 Masters degree programs recommended by CAPES was analyzed. The production corresponds to the period 2000-2003. With these data and considering the titles of the works, they were classified in sub-fields and analysis scales in Geography. The results indicate a displacement of the analysis in Physical Geography for Environmental Geography and a predominance of the Human Geography over the other analyzed fields, besides the prevalence of the analysis in local scale.

Key words: Geography; Research; Teaching.

Recebido em 7 de setembro de 2005, aceito em 2 de outubro de 2005.

\section{Referências}

ALVES, R. (2003) Filosofia da ciência Introdução ao jogo e a suas regras. 7.ed. São Paulo, Loyola. 221p.

BERTRAND, G. (1972) Paisagem e geografia física global: um esboço metodológico. Cadernos de Ciências da Terra, São Paulo, IG/USP, no13.

CAPES - Coordenação de Aperfeiçoamento de Pessoal de Nível Superior. Disponível em: http://www.capes.gov.br/capes/portal/. Acessado em maio, junho e julho de 2005.

HARVEY, D.A. (1993) Condição Pós-Moderna.2.ed. São Paulo, Loyola. $349 p$.

HARVEY, D. (2004) Espaços de esperança. Loyola, São Paulo. 382p.

LATOUR, B. (1994) Jamais fomos Modernos. Tradução de Carlos Irineu da Costa. Rio de Janeiro, Editora 34. 149p.

LEFF, H. (2001).Epistemologia ambiental. São Paulo, Cortez. 240p.
MATURANA, R.H. (1994) Emociones y Lenguaje en Educacion e Politica. Santiago do Chile: Hachette Comunicacion CED Edciones Pedagogicas Chilenas S. A., 98p.

MONTEIRO, C.A.F. (2000) Geossistemas a história de uma procura. São Paulo.Contexto, 127p.

SANTOS, M.A. (1996) Natureza do espaço: técnica e tempo razão e emoção. São Paulo, Hucitec. 236p.

SERRES, M. O. (1990) Contrato natural. Nova Fronteira. 142p.

SUERTEGARAY, D.M.A e NUNES, J.O.R.N. (2000) A natureza da Geografia Física na Geografia.Terra Livre. Paradigmas da Geografia. Parte II n ${ }^{\circ}$ 17.São Paulo: Associação dos Geógrafos Brasileiros, p.1124.

SUERTEGARAY, D.M.A. (2002) Pesquisa e educação de professores. In: PONTUSCHKA, N.N. e OLIVEIRA, A.U. (orgs.). Geografia em Perspectiva. São Paulo, Contexto. p. 109-114. 